Patient decision-making about emergency and planned stoma surgery for IBD: a qualitative exploration of patient and clinician perspectives

Lesley Dibley PhD, Faculty of Education and Health, University of Greenwich, London, UK; Bart's Health NHS Trust, London, UK.

Wladyslawa Czuber-Dochan PhD, Florence Nightingale Faculty of Nursing \& Midwifery, King's College London, UK.

Tiffany Wade, MSc, Florence Nightingale Faculty of Nursing \& Midwifery, King's College London, UK.

Julie Duncan MSc, Guy's \& St Thomas' NHS Trust, London, UK.

Jennie Burch MSc, St Mark's Hospital, Harrow, UK.

Janindra Warusavitarne PhD, St Mark's Hospital, Harrow, UK.

Christine Norton PhD, Florence Nightingale Faculty of Nursing \& Midwifery, King's College London, UK.

Micol Artom, PhD student, Florence Nightingale Faculty of Nursing \& Midwifery, King's College London, UK.

Liam O’Sullivan BA (Hons) PGDip Marie Curie Hospice Hampstead, UK.

Azmina Verjee, Denise Cann, and members of the stoma PPI team

Name and address for correspondence:

Dr Lesley Dibley

Faculty of Health and Education

University of Greenwich (Southwood site)

Avery Hill Road, London, SE9 2UG

Tel: +44 (0)20 83318000 (Switchboard) 
Email: lesley.dibley@gre.ac.uk; no fax available

\section{Sources of support}

This study was funded in full by a Living with IBD award from Crohn's \& Colitis UK, REF: SP2014/2

\section{Conflicts of Interest}

Lesley Dibley: none

Wladyslawa Czuber-Dochan: none

Tiffany Wade: none

Julie Duncan: speakers fees from Takeda, Shire Pharmaceuticals, Janssen, MSD, Allergan none

Jennie Burch: none

Janindra Warusavitarne: none

Christine Norton: speaker's fees from Takeda and Ferring Pharmaceuticals.

Micol Artom: none

Liam O’Sullivan: none

Azmina Verjee: none

Denise Cann: none 


\section{ABSTRACT}

\section{Background}

Many IBD patients worry about stoma forming surgery (SFS), sometimes enduring poor bowel-related quality of life to avoid it. Anticipation of SFS and whether expectations match experience is under-reported. This qualitative study explored influences on patients' SFS decision-making, and compared pre-operative concerns with post-operative outcomes.

\section{Methods}

We purposively recruited participants with IBD from UK hospital outpatient and community sources, and IBD clinicians from public hospitals. Four focus groups and 29 semi-structured patient participant interviews, and 18 clinician interviews were audio recorded, transcribed, and analysed thematically. Participants had a current temporary, recently-reversed, or permanent stoma, or were stoma naïve.

\section{Results}

Four themes emerged: Pre-operative concerns and expectations, Patient decision-making, Surgery and recovery, and Long-term outcomes. Participants and clinicians agreed about most pre-operative concerns, that outcomes were often better than expected, and support from others with a stoma is beneficial. Patient decision-making involves multiple factors, including disease status. Some clinicians avoid discussing SFS, and the phrase 'last resort' can bias patient perceptions; others recommend early discussion, increasing dialogue when medical management becomes ineffective. The post-operative period is particularly challenging for patients. Stoma acceptance is influenced by personal perceptions and preand post-operative clinical and social support.

\section{Conclusion}

Patients need balanced information on all treatment options, including surgery, from an early stage. Early multi-disciplinary team dialogue about SFS, and contact with others living well with a stoma, could enable informed decision-making. Life with a stoma is often better than anticipated, improving quality of life and control. Ongoing specialist nursing support aids recovery and adjustment.

Keywords: Decision-making; Inflammatory bowel disease; Qualitative; Stoma; Surgery 


\section{INTRODUCTION}

Approximately 300,000 people in the UK and 1.6 million in the USA have inflammatory bowel disease (IBD). Annually, 2000 (0.66\%) of these in the UK (1) and an estimated 24,000 $(1.5 \%)$ in the USA (2) undergo surgery resulting in a permanent or temporary stoma. Fear of having a stoma is repeatedly reported as a major concern for people with IBD in many countries (3-8), alongside fatigue, disease and bowel control, and disease unpredictability $(4 ; 5 ; 9)$ but there is no evidence to explain this level of concern. There is minimal evidence on the experience of living with a stoma for IBD or why people are so fearful of stoma-forming surgery (SFS) that they are willing to trade life expectancy to avoid it (10).

One paper reporting the experiences of young adults anticipating surgery for IBD does not specifically address stoma-related concerns (11). Findings focus on general surgery-related concerns of young adults which may not be relevant across a broader age range. Unpublished data from one of our previous studies (12) reflects the commonly-expressed opinion amongst patients that anything is better than having a stoma. This reluctance may lead patients to delay or avoid a stoma, even when it is strongly indicated clinically. Postoperative risks may be higher and adjustment more difficult if delayed surgery means the patient is more critically ill at the time of surgery (13), and avoiding a stoma may commit people to years of living with disabling symptoms (14). In contrast, opting for a stoma can bring anticipation of improvement: 'I'm going to be having a colostomy bag anyway, which actually, strangely, does not bother me as much as ... this ridiculousness of having to go to the toilet ten to fifteen times a day.' (15).

Online stoma forums and advice resources explain surgical procedures and the practicalities of stoma management, and provide support post-operatively, but do not address emotional anticipation of a stoma. This evidence gap is not limited to IBD. Avoiding a stoma is also a major concern amongst patients facing surgery for colorectal cancer (16), but again this concern is unexplained (17). However, spinal cord injury research suggests that qualitative outcomes are positive, with patients reporting that they should have opted for a stoma much sooner (18). Quality of life (QoL) is also improved in those choosing a colostomy to manage intractable faecal incontinence $(19 ; 20)$. 
One recent study reports patients' experiences shortly after stoma surgery (21), but there is no evidence of the experiences of those with IBD who face long-term anticipation of a stoma. Soon after diagnosis, patients may learn that SFS is a potential treatment option in IBD. Consequently, fear of SFS may arise at each disease flare up and whenever the individual faces any surgery. Body image and sexual function are known to be affected following surgery for IBD $(11 ; 21-24)$, but there is no evidence to confirm whether it is these or other aspects, including impact on relationships (25) which drive avoidance of a stoma (10). Many of those facing the possibility of SFS are in their reproductive years; there may be concerns about the impact of a stoma on attracting or keeping a partner, and for women, on being able to achieve and manage pregnancy $(22 ; 26 ; 27)$.

Stoma avoidance may also be linked to cultural taboos, and rules about bowels which normally make defecation invisible (28), so the option of an internal ileo-anal pouch for those with ulcerative colitis (UC) may be more attractive. Additionally, unlike in colorectal cancer, SFS may not be curative, particularly in Crohn's disease (CD) where the need for further surgery is likely (29-31).

A stoma may also represent the loss of ability to maintain defecation via the normal anal route, an aspect reported previously in colorectal cancer patients (32). Our previous research (12), and clinical experience amongst the study team indicates that stomas are often considered the "last resort", and represent the failure of medical management rather than one of the possible treatment choices available to patients and clinicians. Patients may consider that ileo-anal pouch surgery is the better option, but this carries with it the risk of multiple complications - including pouchitis and night time incontinence - while QoL is comparable between pouch and stoma patients $(10 ; 33)$. Similarly, anterior rectal resection surgery for bowel cancer - also avoiding permanent stoma formation - often leads to altered bowel function which negatively affects QoL in up to $85 \%$ of patients (34).

No studies report anticipations of, or decision-making about, SFS in IBD patients. This study therefore aimed to generate evidence to improve informed decision-making about SFS for people with IBD by learning from patient and clinician experience. The research questions were:

1. What are patients' concerns about, and realities of, living with a stoma for IBD, and how does this influence decision-making regarding stoma-forming surgery? 
2. How do patients' and clinicians' perceptions of, and concerns about, stoma-forming surgery for IBD compare?

\section{MATERIALS AND METHODS}

This three-phase exploratory qualitative study (35) collected data via 1) four separate patient focus groups $(A, B, C)$ : those with a current temporary $(A)$; permanent $(B)$; or recently reversed stoma (C); or stoma naïve but worried (D); 2 ) individual interviews with patients; 3) individual interviews with IBD clinicians.

\section{Recruitment}

Patients: using purposive sampling, participants were recruited from IBD nurse clinics and patient databases at two hospitals, from our existing IBD database of research-interested community-dwelling people (all members of the charity Crohn's and Colitis UK [CCUK]), and via the CCUK online members' forum. Maximum variation sampling was used to select from all those volunteering, to achieve demographic and geographic spread.

Clinicians: IBD and stoma nurse specialists, gastroenterologists and colorectal surgeons were recruited using purposive and chain-referral sampling via our clinical networks, and social media advertising via the UK Royal College of Nursing Gastrointestinal Nurses online forum.

\section{Inclusion criteria}

Patients: over 18 years old, living anywhere within the UK, diagnosis of IBD confirmed with endoscopy (clinical population) or self-reported diagnosis of IBD (CCUK population); either A) a current temporary stoma, B) a permanent stoma, formed for IBD $\geq$ three months prior to participation, C) a recently-reversed stoma (between 3 and 24 months prior to participation, or D) stoma naïve but worried about the prospect. Respondents could participate in either a focus group or an interview.

Clinicians: working anywhere within the UK; holding a specialist nursing, physician, or surgical role in IBD, stoma or colorectal care for at least three years; minimum of twenty IBD cases annually. 


\section{Exclusion criteria}

Patients: complex co-morbidities, including diabetes, heart disease and mental ill-health (clinical diagnosis of depression or schizophrenia, for example) as confirmed in patient notes (clinical sample) or self-reported by participants (CCUK sample). The rationale for this exclusion was that it could be difficult to understand if any distress / psychological issues that might emerge in the data were due to the chronic illness, the stoma or concerns about a stoma.

Clinicians: no exclusion criteria.

\section{Patient and public involvement (PPI) team}

Five members of CCUK were recruited to our PPI team. Chaired by an experienced PPI advocate (AV), all had IBD and experience of living with a temporary or permanent stoma over varying time periods, or had concerns about having a stoma, or were the spouse/partner of someone with IBD who had a stoma.

\section{Data collection}

Data were collected via patient focus groups and individual interviews, and clinician individual interviews. All were audio recorded and professionally transcribed. Focus groups provided initial insight and informed the schedules for patient and clinician interviews. Focus groups were facilitated by LD and WCD, observed by LO and MA; patient interviews were conducted by LD and WCD; clinician interviews were conducted by LD.

\section{Focus groups}

Four focus groups were conducted, one for each aforementioned category ( $A, B, C$ or $D)$. These aimed to understand pre-stoma concerns, the experience - including benefits and disadvantages - of living with a stoma, and whether experience matched expectations. Trigger questions, developed from relevant literature and from discussion with the PPI team, initiated discussion [Table 1]. 


\begin{tabular}{|c|c|}
\hline $\begin{array}{l}\text { Trigger questions (use any according to progress of the focus } \\
\text { group) }\end{array}$ & $\begin{array}{l}\text { Valid for focus group: } \\
\text { A (current temporary stoma) } \\
\text { B (permanent stoma) } \\
\text { C (recently-reversed stoma) } \\
\text { D (never had stoma but concerned) }\end{array}$ \\
\hline 1. What is life like for you with a temporary / permanent stoma? & $A, B$ \\
\hline 2. What concerns you about having a stoma? & $\mathrm{D}$ \\
\hline $\begin{array}{l}\text { 3. Before you had the stoma, what concerned you about having } \\
\text { one? }\end{array}$ & $A, B, C$ \\
\hline 4. What did you imagine life would be like with a stoma? & $A, B, C$ \\
\hline 5. What was life actually like for you with a stoma? & $\mathrm{C}$ \\
\hline $\begin{array}{l}\text { 6. How does life with a stoma compare to life before you had a } \\
\text { stoma? }\end{array}$ & $A, B$ \\
\hline $\begin{array}{l}\text { 7. How does life following your reversal compare to life before } \\
\text { the reversal? }\end{array}$ & C \\
\hline 8. How would you feel if your doctor advised a temporary stoma? & $\mathrm{D}$ \\
\hline $\begin{array}{l}\text { 9. How would you feel if your doctor advised a permanent } \\
\text { stoma? }\end{array}$ & $A, C, D$ \\
\hline $\begin{array}{l}\text { 10. How would you feel about having another stoma in the } \\
\text { future? }\end{array}$ & $A, C$ \\
\hline $\begin{array}{l}\text { 11. Why do you think that so many people with IBD are so } \\
\text { against the idea of having a stoma? }\end{array}$ & $A, B, C$ \\
\hline $\begin{array}{l}\text { 12. What would you say to others with IBD who are anxious } \\
\text { about stoma-forming surgery? }\end{array}$ & $A, B, C$ \\
\hline 13. How did you decide to have stoma-forming surgery? & $A, B, C$ \\
\hline $\begin{array}{l}\text { 14. What would help you be able to make a decision about } \\
\text { stoma-forming surgery? }\end{array}$ & $\mathrm{D}$ \\
\hline $\begin{array}{l}\text { 15. Do IBD doctors and nurses and stoma nurses understand } \\
\text { patient anxiety about stoma-forming surgery? }\end{array}$ & $A, B, C, D$ \\
\hline
\end{tabular}

Table 1: Trigger questions used in the four focus groups

\section{Patient interviews}

Twenty-nine individual interviews were conducted with people in each category $(A, B, C$ or D), either face to face in private homes or via telephone according to participant preference. Using topic guides generated from focus group data, emerging themes were explored in detail. Some themes were category-specific (A, B, C or D) whilst others, such as exploring pre-stoma concerns and impact on relationships, were relevant to all groups.

\section{Clinician interviews}

Nineteen semi-structured telephone or face to face clinician interviews explored issues arising from focus groups and patient interviews. The aim was to compare clinicians' perceptions with those of patients. 


\section{Data analysis}

All transcripts were anonymised and analysed using a thematic analysis guided by a pragmatic analytical hierarchy (36). Focus group transcripts were independently reviewed by JB, DC, LD, WCD, LM, LO and CN to identify early issues of interest. $L D$ and WCD subsequently amalgamated findings, confirming key themes which informed the schedule for subsequent patient and clinician interviews [Available online]. All team members contributed to analysis of patient and clinician interviews, reviewing between two and eight transcripts each. During two team meetings, emerging trends in the individual interview data were discussed, developed and final themes established.

\section{Ethical considerations}

Approval was granted by the National Research Ethics Service Committee London - Fulham (Ref: 15/LO/1024). Respondents to recruitment calls received the study information leaflet prior to participation. Focus groups and face to face interview participants provided written informed consent immediately before data collection. For telephone interviews, the informed consent process was recorded on an electronic form and as a digital audio file immediately before data collection. Audio recordings were stored securely. Telephone participants received a copy of the electronic consent form. Focus group participants received a UK $£ 20$ gift card of their choice in recognition of costs incurred to attend.

\section{RESULTS}

Patients: Ninety-six people volunteered for the study. Based on geographical location, 34 people were invited to participate in the focus groups, and 25 accepted. Of these, six either did not attend or cancelled in advance, resulting in 19 participants across four focus groups [Table 2]. Focus groups lasted 80 - 140 minutes.

Sixty-two people were invited to participate in a face to face or telephone interview. Of these, 30 accepted. One cancelled due to illness, resulting in 29 participants [Table 2]. Interviews lasted 23 - 103 minutes.

Clinicians: 24 of 30 invited clinicians responded. Of these, 19 participated in a telephone interview. One gastroenterologist interview was lost due to recording equipment failure, resulting in 18 captured interviews lasting $16-36$ minutes. Clinicians were located across the UK [Table 2]. 


\begin{tabular}{|c|c|c|c|c|}
\hline PARTICIPATION & GENDER & AGE & DIAGNOSIS & ETHNIC GROUP \\
\hline $\begin{array}{l}\text { Focus groups }(n=19) \\
A(n=5) ; B(n=5) ; \\
C(n=4) ; D(n=5)\end{array}$ & Female $(n=10 ; 52 \%)$ & $\begin{array}{l}\text { Range: } 20-73 \text { yrs } \\
\text { Median: } 34 \text { yrs } \\
\text { Mean: } 40.5 \text { yrs }\end{array}$ & $\begin{array}{l}\text { CD: } n=5 \\
\text { UC: } n=14\end{array}$ & $\begin{array}{l}\text { WB }(n=17 ; 89.4 \%) \\
\text { Other White background }(n=1 \text {; } \\
5.2 \%)\end{array}$ \\
\hline $\begin{array}{l}\text { Patient interviews ( } n=29) \\
\text { A }(n=8) ; B(n=8) ; \\
\text { C }(n=8) ; D(n=5)\end{array}$ & Female $(n=21 ; 72 \%)$ & $\begin{array}{l}\text { Range: } 22-58 \text { yrs } \\
\text { Median: } 40 \text { yrs } \\
\text { Mean: } 39.4 \text { yrs }\end{array}$ & $\begin{array}{l}\text { CD: } n=14 \\
\text { UC: } n=14 \\
\text { IBDU: } n=1\end{array}$ & $\begin{array}{l}\text { Indian }(n=1 ; 5.2 \%) \\
\text { WB }(n=28 ; 96.5 \%) \\
\text { Indian }(n=1 ; 3.5 \%)\end{array}$ \\
\hline & & & CLINICAL EXPERIENCE & \\
\hline $\begin{array}{l}\text { Clinician interviews }(n=18) \\
\text { IBD nurses }(n=7) \\
\text { Stoma / pouch / colorectal nurses }(n=4) \\
\text { Gastroenterologists }(n=3) \\
\text { Colorectal surgeons }(n=4)\end{array}$ & Female: $(n=13 ; 72 \%)$ & $\begin{array}{l}\text { Range: } 35-58 \text { yrs } \\
\text { Median: } 47 \text { yrs } \\
\text { Mean: } 46 \text { yrs }\end{array}$ & $\begin{array}{l}3-7 \text { years }(n=3 ; 16.7 \%) \\
8-12 \text { years }(n=5 ; 27.8 \%) \\
13+\text { years }(n=10 ; 55.5 \%)\end{array}$ & $\begin{array}{l}\text { WB: }(n=14 ; 77.8 \%) \\
\text { WI: }(n=2 ; 11.2 \%) \\
\text { Indian: }(n=1 ; 5.5 \%) \\
\text { Other Black background }(1 ; 5.5 \%)\end{array}$ \\
\hline
\end{tabular}

Table 2: Demographic details of study participants CD = Crohn's disease; IBDU = IBD Unclassified; UC = UIcerative Colitis; WB = White British; $W I$ = White Irish 
Building on the focus group findings, individual interview data analysis revealed four themes. These are presented below. Patient participants are represented by pseudonym, gender ( $F=$ female, $M=$ male), age, disease type $(C D, U C$, or IBD-Unclassified (IBD-U)), and source (Focus group: FG-A,B,C or D, or Interview: Int-A,B,C or D); clinical staff are represented by pseudonym, age, gender and clinical specialism. Additional verbatim extracts are available online.

\section{Travelling the path: the starting point of pre-operative concerns and expectations}

Within this theme, the commonest issues were:

1. The surgery itself

2. Social stigma

3. Cultural issues

4. Limitations to social life and activity

The surgery itself

Participants begin their journey towards stoma surgery with their own set of beliefs which underpin this complex decision-making. The enormity of (any) surgery and perceived risks of post-operative pain, infection and long recovery times were mentioned, and patients' concerns about stoma-forming surgery were mostly mirrored by clinicians:

It's body image, effect on relationship, and the fact that it's an operation. And they always think that there's another medicine that might turn the corner. Then finally it's often considered to be a one-way ticket - a permanent stoma, whereas often it's not.'

[Peter, M, 49, colorectal surgeon]

\section{Social stigma}

Across all groups, concerns focussed on social and interpersonal aspects. Pre-operatively, participants had been or were currently worried that after surgery, the stoma bag would leak, they would carry a noticeable unpleasant smell, and the bag would be visible to others: 
'I was worried about silly things like would people be able to see it? Would you be able to wear clothes normally? Would I ever be able to go skiing again? - that sort of thing. '

[Daisy, F, 35, UC, Int-B]

Social stigma arose from concerns about faecal matter being in an external bag on the abdomen - rather than where it should be (inside and unseen), and from worries about others' judgements of them due to the abnormal management of this bodily function.

\section{Cultural issues}

Cultural and religious factors could be challenging for those with an Indian / Hindu background, but beneficial for those from other communities:

'It's just that you're part of the community...everyone knows everything, nothing is private, you know. And if you say there's something wrong with me or I've got a stoma, it's just gossip ... like, "Do you know what? So and so's daughter or so and so's wife, you know she 's...", [Shobna, F, 41, UC, FG-D]

These factors also present challenges for clinicians by affecting their willingness to discuss surgical options with patients.

\section{Limitations to social life and activity}

Interpersonal concerns included the belief that currently single participants would not be able to find and maintain a loving relationship, and that existing relationships would be damaged as participants believed they would no longer be attractive to their partner. Female participants also worried about the impact of a stoma on their ability to bear children. The prospect of a stoma was viewed negatively; participants expected it would ruin their life, they would have poor control over bowel function, and currently-enjoyed sporting and other energetic activities would have to be forfeited:

'That's one more thing that might stop me playing football, which I wouldn't want to do and ... having a sex life, going for a swim, sitting on the beach.'

[Karl, M, 55, UC, FG-D] 
Concerns often arose following negative experiences of a participant's own previous stoma, or others' stomas or from social representations which include the perceptions that stomas are dirty and an abnormality, and are only for older people. Some clinicians also identified age as a factor, perceiving that a stoma would be less acceptable to younger patients, but participants did not necessarily agree with this view, with young adults often recognising that having a stoma had enabled them to pursue education and career pathways [See also online file: Table A].

\section{Travelling the path: patient decision-making}

Within this theme, the key issues were:

1. Information seeking or avoidance

2. Early provision of SFS information to patients

3. Communication, language and rapport

4. Stoma buddies

\section{Information seeking or avoidance}

There are many paths towards decision-making for stoma-forming surgery. For some it is a more straightforward and direct journey, whilst for others it is convoluted and difficult. Information-gathering and processing can feel overwhelming as the person with IBD tries to balance their initial fears, concerns and experiences with their existing attitudes towards toileting and bodily waste, and the demands of their disease. Typically during this stage of the journey there is either deliberate effort to avoid information, or there is active research - especially online - and willingness to meet others with a stoma either virtually or in person.

Information-seeking or avoidance appears to be influenced by several key elements including illness duration (longer illness = greater willingness to consider stoma), when and by whom the topic of surgery has been introduced, age, and rapport and communication with the health professional team [Table 3]. 


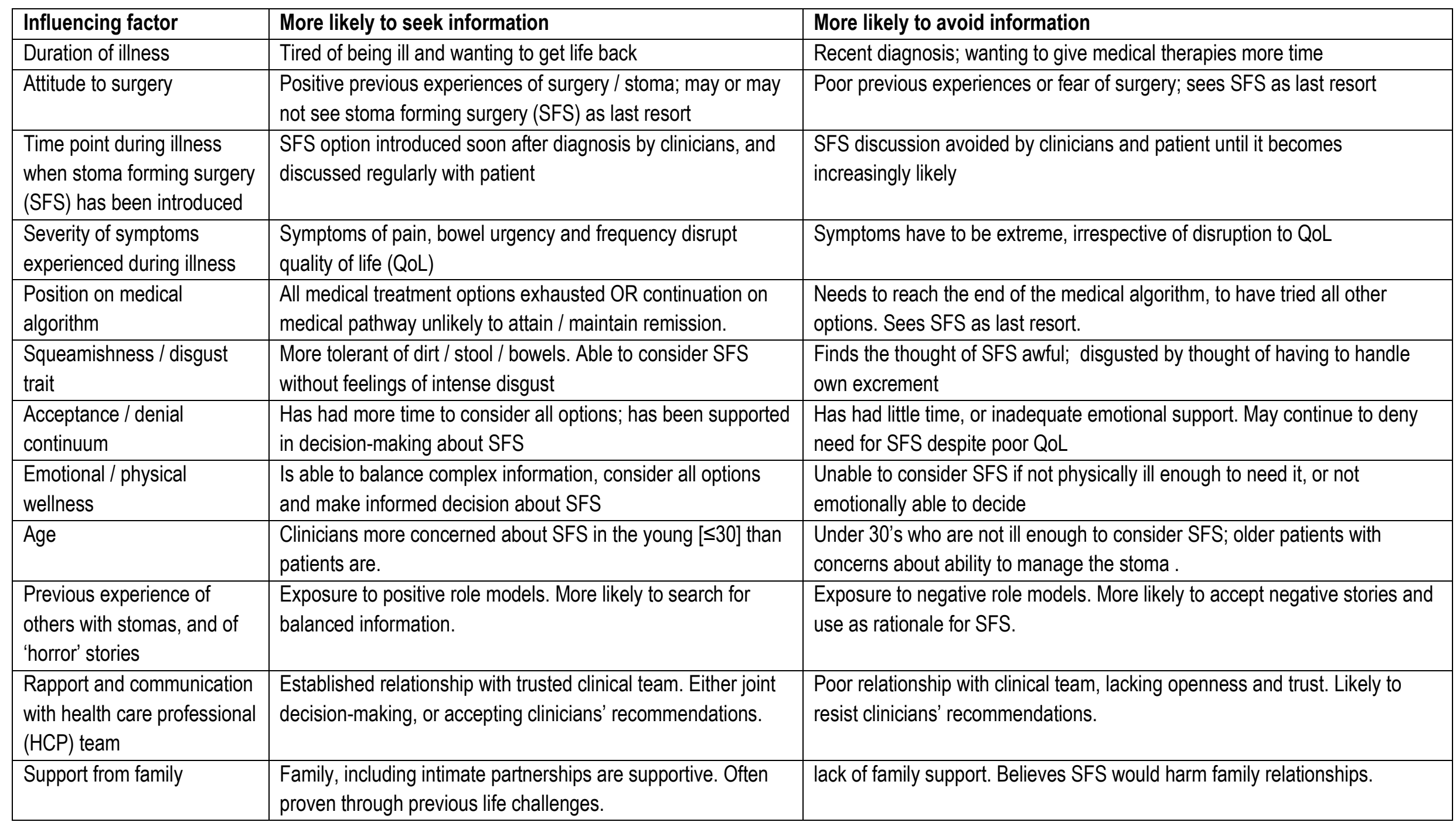

Table 3: Factors which influence patients to seek or avoid information about stomas 
In particular, there is discrepancy of opinion between participants and clinicians regarding the 'right' age for a stoma, and when the option of SFS should be introduced. Failure to offer SFS in a timely manner can commit the patient to years of debilitating symptoms:

'It wasn't offered to me ... I'd never thought of it as an option, that you can actually decide that you don't want this awful bowel inside you anymore.'

[Doreen, F, 61, UC, Int-B]

\section{Early provision of SFS information to patients}

All IBD, stoma and colorectal nurses, and a minority of gastroenterologists agreed that early introduction of the medical and surgical management options for IBD is preferable. This lays the foundation for returning to discussion of surgical management and stomas if needed:

As soon as they're diagnosed, I always talk about surgery up front, because I think that just raises it in their mind. And then they're given an information pack, all about $I B D$, which mentions surgery and stomas. That initial introduction is really important, because it gets it on the radar as a possibility.'

[Linda, F, 38, IBD Nurse]

Other gastroenterologists felt the topic should be avoided, believing this protects the patient from unnecessary concern. However, all clinicians agreed that patients ideally need adequate time to make the decision for stoma-forming surgery, and for some, this may be of considerable duration. Participants stressed the importance of receiving the necessary information sufficiently in advance, so that they can make the decision before they are acutely or critically ill. The challenge for clinicians is to provide this information, when, as participants recognised, a stoma is something that psychologically, they may not want to contemplate. Participants indicated that it is challenging to actively seek information from their clinical team about stomas, without giving the impression that they want one imminently.

\section{Communication, language and rapport}

An important part of the decision-making stage is communication and rapport with clinicians and introducing the topic of SFS to patients, although clinicians had varying perceptions on attitudes towards, and the role of, stomas in managing IBD. Some felt that 
SFS was currently perceived as the last resort, whilst others reported that although this was previously the case, it was now seen as a therapeutic option.

The language of a stoma as 'the last resort' sends messages of medical failure, whilst presenting stoma information in a more positive light may send a different message to patients:

'The words I hate to hear mentioned are 'failure of medical therapy.' That very word 'failure' - immediately the patient sees it in the context of them and their disease. So the word 'option' I bring up really early on. There 's an option.'

[Anita, F, 44, consultant gastroenterologist]

Some participants avoided contemplating stoma surgery because of the sense of finality it represents, whilst others needed to have exhausted all other medical options before feeling ready to accept inevitable stoma surgery. Although this approach could reassure participants about finally deciding for SFS, others felt angry and frustrated at having subjected their bodies to the side-effects of powerful drugs for many years to no avail, and ending up with a stoma anyway. Participants and clinicians placed value on sharing honest, balanced information from a consistent multidisciplinary team, and participants wanted to hear the truth about possible complications of surgery and the initial difficulties faced during the early stoma management phase. All study participants offered ileo-anal pouch surgery had been informed of the potential risks, and this insight enabled some to discuss and agree with their surgeon the best way to plan for pregnancy.

\section{Stoma buddies}

For many patients, fear of a stoma represents fear of the unknown. One strategy which all participants and most clinicians considered beneficial for patient decision-making, was to meet another person of the same gender, age and life situation, who was living well with a stoma:

'You can have the most wonderful stoma nurse in the world, [but] what you want is somebody, roughly your own age who's lived it.' [Rachel, F, 31, UC, Int-A]

Patients also need information which dispels fear of the unknown. Stoma naïve participants often had no idea what a stoma looks like; they wanted to see realistic images of a newly- 
created stoma, and how it looks some months later. Practicing with the stoma bag prior to surgery also helped participants overcome concerns about visibility, body image, and impact on their choice of clothing. The final decision to have stoma-forming surgery is often ultimately driven by disease status and dwindling self-assessed QoL, but participants retain their underlying social, interpersonal, cultural and practical concerns [See also online file: Table B].

\section{Travelling the path: surgery and recovery}

Within this theme, key issues were revealed as:

1. Emergency or planned surgery

2. Types of surgery, previous surgery and complications

3. Expectations of stoma management

4. Relationships with healthcare professionals during the recovery period

As for all stages of this journey, the length and duration varies for each person. Physical and emotional recovery and outcomes are influenced by the key issues outlined above. Wellness (recovery), practical stoma management and emotional adjustment all influence a person's future relationship with their stoma.

\section{Emergency or planned surgery}

There are benefits and disadvantages of emergency and planned stoma surgery for participants. Although it may not always be the case, rapid escalation from diagnosis to SFS is often devastating for the patient:

'I got ill in the September and I had my colon removed end of that same month. So it's all out, totally sudden, no symptoms, just three weeks after feeling a bit ill, I had my colon removed. And that was quite a big shock.' [Pauline, F, 64, UC, FG-B]

A long delay in diagnosis leading immediately to stoma forming surgery could prompt positive reactions and a sense of relief. In contrast, planned surgery enabled participants to prepare psychologically and physically, yet prolonged the anticipation. 
Types of surgery, previous surgery and complications

Prior experience of operations meant some participants felt they knew what to expect from surgery, whilst for others, it served to remind them of the challenges. For many, a temporary stoma was easier to deal with emotionally as it felt less final, and offered the option of reversal. Clinicians and participants agreed that the quality of the temporary stoma experience had a powerful impact on, and was critical to, participants' overall assessment of the experience and their ability to consider living in the future with a permanent stoma:

'You've got to make it a good stoma, that's one of the reasons why I tend to make end ones. And often with pouches the temporary loop they have, when the pouch is formed, is not a very good stoma. So they're having high up horrible loop ileostomies. So often an end stoma is a much, much better stoma.'

[Sarah, F, 51, colorectal surgeon]

The importance of creating a 'good' temporary stoma was reflected amongst participants who, struggling to manage a troublesome loop ileostomy, were keen to avoid any future permanent stoma. Aside from a period of adjustment to the practicalities of managing a stoma, most participants had not encountered problems arising from stoma placement. Only one had endured major post-operative complications and significant risk to his life. Having travelled a lengthy path to reach the decision to have surgery, this experience caused him to doubt that decision.

\section{Expectations of stoma management}

Participants and clinicians expected there to be a period of adjustment to living with a stoma, although this focussed on the practical issues, such as working out the routine for changing the appliance, and finding the right stoma bag. Some participants were not aware that alternative bags were available, and struggled on with the type they left hospital with, often experiencing frequent leakages. This situation was most likely to occur where followup stoma services or relationships with healthcare professionals were poorer.

There was often initial reluctance to look at the stoma post-operatively, although some overcame this more quickly than others. Most participants experienced good post-operative practical support from clinicians, but emotional support was often lacking, leaving them 
feeling abandoned. Some participants felt a sense of loss and grief, which coincided and contrasted with relief that they were no longer ill; these layered emotions could resurface over time.

Learning practical stoma management whilst dealing with the emotional impact and physical changes can be difficult and frustrating. In the early post-operative stages, the concerns participants had at the outset may persist. Particularly, fears of being 'found out' and being judged as 'abnormal' by others, of others witnessing leakages or noises, and concerns about intimacy may be enhanced immediately post-operatively. Strategies which help patients remember their pre-surgery life can encourage them through challenging post-operative periods:

I sometimes get them to write down what is life like now, so if they do end up having surgery, and they're having a bad day post-op, that they've got something to reflect back on.' [Joyce, F, 39, stoma nurse]

A grief / loss experience is likely and may be more pronounced in emergency situations, centred on either loss of the imagined or hoped for future, or of the body part despite its defectiveness. Early awareness of the possibility of SFS enables the grieving process for the potential loss to begin, and can also help determine the conditions under which patients would consent to such surgery.

Relationships with healthcare professionals during the recovery period Most participants had access to ongoing post-operative and post-discharge support from clinicians, particularly stoma nurses. Those who had no support, or were not aware that there was a stoma service in their area, felt abandoned and distressed:

'They were good for the initial six weeks, the same as the surgeon. But then it was, "You're done now, we don't want to hear from you.", [Marie, F, 46, CD, Int-B] Some form of follow-up beyond the immediate post-operative period was desired by several participants, and may be particularly necessary for those who have a challenging emotional and / or physical recovery [See also online file: Table C]. 


\section{Travelling the path: towards long term outcomes}

Within this theme, the key aspects were:

1. The post-operative temporary stoma experience

2. Impact of a permanent stoma

3. Dispelling pre-operative concerns and anxieties

Although some patients for personal, psychological or cultural reasons cannot make the adjustment, most participants with any experience of a stoma agreed that outcomes were almost always better than anticipated, a view reflected by clinicians:

'Even though the perception is that the stoma would be life-changing, the actual reality is it's life-improving.' [Louise, F, 47, IBD Nurse]

For the majority, however, the longer term outcomes are positive, but vary according to the experiences and concerns reported above. Some participants who did not like having a stoma still recognised the positive impact it has had on their life and wellbeing, although the duration of illness and ability to compare one's life prior to and after stoma was important. Those with short illness duration who travel from diagnosis to stoma in a few weeks can find it emotionally challenging.

The post-operative temporary stoma experience

The experience of recovering with a temporary stoma had a profound impact on participants' ability to consider a stoma as a permanent option in the future. Some, particularly where there was lengthy recovery due to infection / complications, and high number of surgeries, found it so challenging that once they had the stoma reversed they would not want another. Others found themselves able to cope with a temporary stoma, and thus able to accept a possible future permanent stoma. However, sometimes those with temporary stomas may not invest the emotional effort required to adjust, bracketing the experience from the rest of life:

'I think it says quite a lot about me, that I didn't tell my [teenage] children that I was having one. They still don't know. I hid it from them successfully for five months. I don't know if that was a good thing to do or not.' [Penelope, F, 53, CD, Int-C] 
Some participants who had imagined 'temporary' to mean perhaps three to five months, were still living with their 'temporary' stoma several years later. Sometimes this was their choice, as participants found themselves feeling so well they chose to reject the planned reversal surgery but more often it was guided by clinical recommendation. Uncertainty over the length of the temporary period can leave some patients in a long term state of indecision and low commitment to living with and adjusting to the stoma.

\section{Impact of a permanent stoma}

Most participants with a permanent stoma found that they felt better immediately postoperatively, giving them insight into how unwell they had been and how much pain, discomfort and disruption they had been accommodating:

'I don't think I realized how unwell I was until I woke up and felt better. And I literally did wake up and feel better. I think you almost get used to it, I think you adapt to the lot you're given, so you get on with it.' [Esther, F, 26, UC, Int-B]

After a process of loss and grief, acceptance, and becoming competent in stoma management, participants saw the stoma as life-enabling. This process of acceptance and positive regard for their stoma seemed quicker and smoother for participants who learnt about the possibility of SFS early on in their illness experience, who proactively researched stoma options, and who engaged with similar others who had positive experiences of stomas. They also had access to practical tips about stoma management via stoma nurses and support sites, and had supportive families, friends and / or mentors. This lay support seems particularly beneficial in addressing the emotional implications of surgery.

\section{Dispelling pre-operative concerns and anxieties}

Almost all participants, whether they liked their stoma or not, reported that outcomes had been far better than expected, and their initial concerns had often proved unfounded.

Other people didn't seem to notice any smell and could not see the stoma bag under their clothes, and intimate partners were not put off by the stoma:

'My husband is absolutely amazing, just every single day tells me that I'm beautiful and like he really doesn 't care what I look like and he's completely accepted it'.

[Helen, F, 23, CD, Int-A] 
For some, the presence of the stoma was bothersome to them, rather than their partner, whilst another regretted that the stoma bag created a physical barrier which prevented total skin to skin contact with her husband during intimacy. For others, the bag and related odour was a source of amusement.

Participants who chose to disclose their stoma to loved ones, friends, work colleagues and acquaintances often experienced a positive response. Sometimes, their interlocutor revealed that they, a family member or friend also had a stoma. This often came as a welcome surprise to participants, confirming that a stoma is not visible to others. Furthermore, rather than being a hindrance and life-reducing, their stoma was lifeenhancing. They were now able to enjoy many activities denied them whilst ill, including sports (football, rugby, swimming), employment, social activities and dining. Travelling by car, train or plane became easier, and although additional planning might be required, any inconvenience associated with the stoma was overshadowed by the enjoyment of their new-found freedom.

Some participants did experience occasional gurgling sounds or leaks from their bags, but this was less problematic than originally imagined. Although appliance leaks tended to be major, these occurred infrequently and were often due to the bag being a poor fit, or a tried and tested application technique inexplicably failing. Some participants described handcutting their appliances for a better fit, and seemed unaware of available appliance -cutting services or alternative sizes and types of bags which might suit them better. Those who coped best tended to see these issues as minor in comparison to their pre-stoma illness experience. They also planned their stoma management more effectively, including identifying the optimum time and place for changing the bag based on learning when the stoma would be more or less active. Interestingly, although colectomy and eventual reversal of the stoma might suggest a person with UC is clinically 'cured', one patient's perspective was that a physical imprint of their experience always remains [See also online Table D]:

'Just because [the colon] isn't there, it's a bit like with drawing, if you have a blank sheet of paper and you do a pencil mark on it and rub it out, you don't go back to having a blank sheet of paper'. [Karen, F, 43, UC, Int-C] 


\section{Discussion}

Patient decision-making about SFS is complex and primarily driven by disease status, but also influenced by pre-existing psycho-social and emotional aspects, and concerns about the potential negative impact of a stoma.

There were more similarities than differences amongst participants, and between participants and clinicians. Opinions differed most in relation to the age at which a stoma is acceptable for patients, and when SFS information should be introduced. Assumptions that stomas are more acceptable amongst older people, so that clinicians avoid or delay offering this to younger patients, may be misguided. Older people may struggle more with practical stoma management as mobility, dexterity and perhaps cognitive ability decrease $(37 ; 38)$, or alteration in body mass affects stoma care (39). Conversely, it should not be assumed that young adults are always more concerned about body image and relationships, and would prefer to struggle through a medical treatment pathway. For some, a stoma may enable effective pursuit of education and employment.

Emergency SFS seems to be more physically and emotionally challenging for the patient than planned surgery, although it has been reported that there is no correlation between timing of surgery and anxiety, depression, and health-related quality of life (40). Early introduction of stoma surgery information, with discussion escalating if medical therapies prove ineffective, is likely to enhance informed decision-making by raising patient awareness of all available treatment options. If the patient does then progress towards surgery, they will have had time to consider, research, and discuss the options with family and friends.

Patients go through a grieving process after SFS - for the loss of their normal body function and appearance, and of their hoped-for future $(41 ; 42)$. Accurate, balanced information, delivered in a timely manner, can aid the grieving process. Presenting stomas as a sign of treatment failure, and as a last resort, sends negative messages to patients that a stoma is something to be avoided. Patients may perceive an element of trial and error if clinicians seem unsure about proceeding towards SFS (43). 
Participants and clinicians independently identified similar factors which enabled patient decision-making for SFS and which facilitated adjustment in the immediate and long-term post-operative periods. The most beneficial factor was contact with a 'stoma buddy' another person of similar age, life-situation, and of the same gender, who was living well with a stoma and acted as a role model. Evidence that an active, productive, healthy life was possible with a stoma, and reassurances from others who were living the experience was recognised by all participants as more beneficial than reassurances coming from clinicians. Ongoing contact with the stoma buddy throughout the post-operative period facilitates practical management of the stoma, which may in turn contribute to emotional wellbeing.

Experience of wearing a stoma bag pre-operatively can help ease patients' concerns and inform accurate siting of the stoma. Stoma siting is a skilful task, and when carried out by a specially-trained stoma nurses, improves patient outcomes $(44 ; 45)$. Poor siting increases the risk of post-operative complications, including fecal spillage into the abdominal wound (46). Providing patients pre-operatively with real images illustrating the appearance of the stoma in the immediate post-operative period and how this changes as recovery progresses, gives them a clear idea of what to expect. There is plentiful evidence from all areas of healthcare that patients who have been informed with realistic, honest and accurate information, cope better with illness, hospitalisation, and surgery (47-49).

The immediate post-operative period can be very challenging and patients need emotional as well as practical support. Patients have often struggled to choose SFS, and post-operative problems may further challenge their certainty about the decision they made. Keeping a pre-operative diary to refer back to can remind patients of why they decided to choose surgery, and reinforce their faith in their decision. The type and quality of support, particularly from stoma nurses, is instrumental to the patient's recovery (50). Some clinical units offer an open door policy to patients post-surgery for as long as they need it, but others do not - and patients without access to follow-up care seem to struggle more postoperatively, especially with finding the right equipment to manage their stoma well (51-53).

The experience a patient has with a temporary stoma influences their perceptions of any potential future permanent stoma; the quality of surgery to form the stoma is critical to the patient's subsequent stoma experience; stoma formation should be carried out by 
experienced surgeons $(46 ; 50)$. A temporary loop ileostomy may be technically easier to create and reverse, presenting fewer surgical and anaesthetic risks to the patient. However, "temporary" can be for prolonged periods, or may be repeated several times in IBD, and QoL with the temporary stoma should be considered (46).

Participants and clinicians independently agreed that for the majority of patients, long-term outcomes were very much better than anticipated, with many pre-operative concerns proving unfounded. This pattern has previously been reported anecdotally from clinical experience, and in research in relation to other conditions $(18 ; 20 ; 54)$ as well as in IBD $(55 ; 56)$. For participants in this study, relationships were created and sustained, babies conceived, carried and delivered, and lifestyles enhanced through regular employment, travel and sporting and social activities.

Resistance to stoma surgery appears to be underpinned by social attitudes towards excreta, and by perceptions that life would be severely limited by a stoma. Social representation theory addresses the manner in which a central stock of values, ideas, metaphors, beliefs and practices that are shared amongst the members of communities, influence community behaviour (57). In respect of managing stool, social representations mean that humans are socialised towards private containment and control of body fluids and products. 'Matter out of place' (58) such as stool in a bag outside the abdomen, challenges these social representations and may explain some of the resistance towards stoma surgery. Further explanation may come from the stigma that arises from 'not being normal'. Goffman's theory of impression management (59) argues that humans expend significant effort to present an acceptable face to the world. Anything which marks a person as different from those social representations, the 'norms' of social interaction, can potentially stigmatise (60). The drive to fit in is so strong that people will actively avoid anything, such as a stoma, which marks them as different.

The period of emotional adjustment to and acceptance of a stoma varies, but may be influenced by the individual's pre-existing illness perceptions and coping styles (61) and extended when there is pre-operative resistance to surgery or where the person is appalled or disgusted by the notion of 'dirty matter out of place.' The personality characteristic of disgust trait (62), which influences a person's response to dirty matter, has been shown to 
influence the way others respond to a person with a colostomy (63). Personality and disgust trait may therefore play a part in the response of some IBD patients to the prospect and reality of stoma surgery. There is potential to measure disgust trait and any relationship with personality, as a means of predicting response to stoma.

To improve patients' overall experience of living with a stoma, clinicians can ensure information regarding surgery including SFS, is provided at diagnosis, and that SFS is presented as a treatment option rather than a last resort. Prior to surgery, contact with stoma buddies, specialist stoma and IBD nurses and relevant support groups, and provision of information that includes real photo images of new and settled stomas, will aid decisionmaking. Peri-operatively, formation of the best possible stoma, even if temporary, will likely enhance the stoma experience for the patient. Post-operatively, recognition of and support for the emotional and physical adjustment required will be beneficial, with follow-up for as long as the patient needs it. Open, honest and inclusive communication between relevant clinicians, the patient and their family, is essential.

Patient-reported evidence of the realities of living with a temporary or permanent stoma, combined with existing QoL studies (64-66) can inform patient decision-making, reduce preand peri-operative anxiety and potentially enhance post-operative outcomes. This knowledge may inform development of tailored pre-operative interventions according to individual need, including full discussion of all surgical options (67). The benefits of early pre-operative support and preparation are known to improve outcomes, including acceptance of a stoma, after surgery $(17 ; 44 ; 68 ; 69)$. Findings may also be transferable to other conditions where stoma formation may be required.

\section{Limitations}

All participants were self-selected and almost all were Caucasian. Findings may therefore not reflect the views and experiences of patients with different disease severity and / or stoma outcomes, or patients and clinicians from other ethnic groups. Purposive recruitment from hospital clinics had to be suspended as researchers found that in some cases, they were introducing the topic of stomas to patients' naïve to this information, which could 
have potentially caused distress to patients. Clinical colleagues instead identified possible participants from their patient databases, who were subsequently invited to the study by the research team. This may have biased the demographic and gender profile of the study participants. Lower than planned numbers in two of the focus groups, more female participants, and more participants with UC, may have influenced the final results.

\section{Conclusion}

Patient decision-making about stoma forming surgery is complex. Disease status is the dominant, but not the only, deciding factor. Patients need balanced information on benefits and challenges of all treatment options including surgery, from an early stage. Multidisciplinary team dialogue about likely SFS should begin at the first indication that medication is not controlling disease or symptoms. Using negative language and discussing SFS as a "last resort" is unhelpful to patients. It is incumbent upon clinicians to provide the best stoma experience possible for the patient. Patients and clinicians agree that support from similar others with a stoma is highly effective at reducing a patient's concerns. For most, pre-operative social, psychological and emotional concerns prove unfounded. Life with a stoma is often much better than anticipated, improving QoL and control, and ongoing IBD and stoma nurse support aids patients' recovery and adjustment. Future research to predict patient response to stoma may enable clinicians to provide targeted pre- and postoperative support strategies.

Reference List

(1) Mowat C, Cole A, Windsor A, et al. Guidelines for the management of inflammatory bowel disease in adults. Gut 2011;60:571-607.

(2) Beddy D, Dozois E, Pemberton J. Perioperative complications in inflammatory bowel disease. Inflamm Bowel Dis 2011;17:1610-9. 
(3) Armuzzi A, Riegler G, Vecchi M, et al. Epidemiological features and disease related concerns of a large cohort of Italian patients with active Crohn's disease. J Crohn's Colitis 2014;8:S332.

(4) Casati J, Toner B, De Rooy E, et al. Concerns of patients with inflammatory bowel disease: a review of emerging themes. Dig Dis Sci 2000;45:26-31.

(5) Lesage A-C, Hagège $H$, Tucat $G$, et al. Results of a national survey on quality of life in inflammatory bowel disease. Clin Res Gastroenterol and Hepatol 2011;35:117-24.

(6) Canavan C, Abrams K, Hawthorne B, et al. Long-term prognosis in Crohn's disease: factors that affect quality of life. Aliment Pharmacol Ther 2006;23:377-85.

(7) Levenstein S, Zhiming L, Almer S, et al. Cross-cultural variation in disease-related concerns among patients with inflammatory bowel disease. Am J Gastroenterol 2001;96:1822-30.

(8) Stjernman H, Tysk C, Almer S, et al. Worries and concerns in a large unselected cohort of patients with Crohn's disease. Scand J Gastroenterol 2010;45:696-706.

(9) Jelsness-Jorgensen L, Moum B, Bernklev T. Worries and concerns among inflammatory bowel disease patients followed prospectively over one year. Gastroenterol Res Pract 2011; Article ID 492034: 8 pages. Available at: http://dx.doi.org/10.1155/2011/492034.

(10) Byrne C, Tan K, Young J, et al. Patient and clinican preferences for surgical and medical treatment options in ulcerative colitis. Colorectal Dis 2013;16:285-92.

(11) Allison M, Lindsay J, Gould D, et al. Surgery in young adults with inflammatory bowel disease: a narrative account. Int J Nurs Stud 2013;50:1566-75.

(12) Dibley L, Norton C. Experiences of fecal incontinence in people with inflammatory bowel disease: self-reported experiences among a community sample. Inflamm Bowel Dis 2013;19:1450-62.

(13) Wilson J, Lidgerwood A, Knowles S, et al. Psychological impact of a stoma in patients with Crohn's disease. J Gastroenterol Hepatol 2008;23(Suppl.4):A192. 
(14) Neumann P-A, Menningen R, Senninger N, et al. Timing of restorative proctocolectomy in patients with medically refractory ulcerative colitis: the patient's point of view. Dis Colon Rectum 2012;55:756-61.

(15) Dibley L. The experience of stigma in inflammatory bowel disease, with or without incontinence: a hermeneutic phenomenological study. University of Coventry (PhD thesis); 2014; p.328.

(16) Holzer B, Gyasi A, Schiessal R, et al. Patients' expectations of colorectal surgery for cancer. Colorectal Dis 2006;8:186-91.

(17) Brown $\mathrm{H}$, Randle J. Living with a stoma: a review of the literature. J Clin Nurs $2005 ; 14: 74-81$.

(18) Coggrave M, Ingram R, Gardner B, et al. The impact of stoma for bowel management after spinal cord injury. Spinal Cord 2012;50:848-52.

(19) Colquhoun P, Kaiser RJ, Efron J, et al. Is the quality of life better in patients with colostomy than patients with fecal incontinence? World J Surg 2006;30:1925-8.

(20) Norton C, Burch J, Kamm M. Patient's views of a colostomy for fecal incontinence. Dis Colon Rectum 2005;48:1062-9.

(21) Persson E, Hellström A-L. Experiences of Swedish men and women 6 to 12 weeks after ostomy surgery. J Wound Ostomy Continence Nurs 2002;29:103-8.

(22) Muller K, Prosser R, Bampton P, et al. Female gender and surgery impair relationships, body image and sexuality in inflammatory bowel disease: patient perceptions. Inflamm Bowel Dis 2010;16:657-63.

(23) Cohen A. Body image in the person with a stoma. J Enterostomal Ther 1991;18:6871.

(24) Carlsson E, Bosaeus I, Nordgren S. What concerns subjects with inflammatory bowel disease and an ileostomy? Scand J Gastroenterol 2003;38:978-84.

(25) Cakmak A, Aylaz G, Kuzu M. Permanent stoma not only affects patients' quality of life but also that of their spouses. World J Surg 2010;34:2872-6. 
(26) Junkin J, Beitz J. Sexuality and the person with a stoma. J Wound Ostomy Continence Nurs 2005;32:121-8.

(27) Maunder R, Toner B, De Rooy E, Moskowitz M. Influence of sex and disease on illness-related concerns in inflamamtory bowel disease. Can J Gastroenterol 1999;13:728-32.

(28) Rozmovits L, Ziebland S. Expressions of loss of adulthood in the narratives of people with colorectal cancer. Qual Health Res 2004;14:187-203.

(29) Ecker K, Glerend M, Kreissler-Haag D, et al. Reoperations at the ileostomy in Crohn's disease reflect inflammatory activity rather than surgical stoma complications alone. Int J Colorectal Dis 2001;16:76-80.

(30) lesalnieks I, Schlitt H. Outcome of temporary stoma closure in patients with Crohn's disease. Colorectal Dis 2011;13(Suppl.6):21.

(31) Koriche D, Gower-Rousseau C, Chater C, et al. Post-operative recurrence of Crohn's disease after definitive stoma: an underestimated risk. Int J Colorectal Dis. 2017; 32:453-458.

(32) Macdonald L, Anderson H. Stigma in patients with rectal cancer: a community study. J Epidemiol Comm Health 1984;38:284-90.

(33) Camilleri-Brennan J, Munro A, Steele R. Does and ileoanal pouch offer a better quality of life than a permanent ileostomy for patients with ulcerative colitis? $\mathrm{Br} \mathrm{J}$ Surg 2000;87(Suppl.1):47.

(34) Battersby N, Juul T, Christensen P, et al. Predicting the risk of bowel-related quality of life impairment after restorative resection for rectal cancer: a multicenter crosssectional study. Dis Colon Rectum 2016;59:270-80.

(35) Stebbins R. Exploratory Research in the Social Sciences. Thousand Oaks, CA: Sage; 2001.

(36) Spencer L, Ritchie J, O'Connor W. Analysis: Practices, Principles and Processes. In: Ritchie J, Lewis J, editors. Qualitative Research Practice: a guide for social science students and researchers.London: Sage Publications Ltd; 2003: 199-218. 
(37) Bentley A. Stoma Care: Older Adults. PACEsetterS 2012;9:23-5.

(38) Burch J. Making maintaining dignity a top priority: caring for older people with a stoma in the community. Br J Community Nurs 2016;21:280-2.

(39) Skeps R, McMullen C, Wendel C, et al. Changes in body mass index and stoma related problems in the elderly. J Geriatr Oncol 2013;4:84-9.

(40) Knowles S, Wilson J, Wilkinson A, et al. Psychological wellbeing and quality of life in Crohn's disease patients with an ostomy. J Wound Ostomy Continence Nurs 2013;40:623-9.

(41) Kelly M. Loss and grief reactions as responses to surgery. J Adv Nurs 1985;10:51725.

(42) Maguire P, Parkes C. Surgery and loss of body parts. BMJ 1998;316(7137):1086-8.

(43) Krieger J. Last resort or roll of the die? Exploring the role of metaphors in cancer clinical trials education among medically underserved populations. J Health Commun $2014 ; 19: 1161-77$.

(44) Kozell K, Frecea M, Thomas J. Preoperative ostomy education and stoma site marking. J Wound Ostomy Continence Nurs 2014;4:206-7.

(45) McKenna L, Taggart E, Stoelting J, et al. The impact of preoperative stoma marking on health-related quality of life. J Wound Ostomy Continence Nurs 2016;43(1):57-61.

(46) Brand M, Dujovny N. Pre-operative considerations and creation of normal ostomies. Clin Colon Rectal Surg 2008;21:5-16.

(47) Gallefos F, Bakke P. Impact of patient education and self-management on morbidity in asthmatics and patients with chronic obstructive pulmonary disease. Respir Med $2000 ; 94: 279-87$.

(48) Johansson K, Nuutila L, Virtanen H, Katajisto J, Salantera S. Preoperative education for orthopaedic patients: systematic review. J Adv Nurs 2005;50):212-23.

(49) Kruzik N. Benefits of preoperative education for adult elective surgery patients. AORN Journal 2009;90:381-7. 
(50) Hendren S, Hammond K, Glasgow S, Perry W, Buie D, Steele S, et al. Clinical practice guidelines for ostomy surgery. Dis Colon Rectum 2015;58:375-87.

(51) Burch J. Follow-up appointments after stoma formation: a literature review. Gastrointestinal Nurs 2016;14:26-31.

(52) Zhang J-E, Wong F, You L-M, Zheng M-C, Zhang B-Y, Huang M-R, et al. Effects of enterostomal nurse telephone follow-up on post-operative adjustment of discharged colostomy patients. Cancer Nurs 2013;36:419-28.

(53) Claessens I, Probert R, Tielemans C, Steen A, Nilsson C, Andersen B, et al. The Ostomy Life Study: the everyday challenges faced by people living with a stoma in a snapshot. Gastrointestinal Nurs 2015;13:18-25.

(54) Silva M, Ratnayake G, Deen K. Quality of life of stoma patients: temporary ileostomy versus colostomy. W J Surg 2003;27:421-4.

(55) Camilleri-Brennan J, Steele R. Objective assessment of quality of life following panproctocolectomy and ileostomy for ulcerative colitis. Ann R Coll Surg Engl $2001 ; 83: 321-4$.

(56) Kuruvilla K, Osler T, Hyman N. A comparison of the quality of life of ulcerative colitis patients after IPAA vs lleostomy. Dis Colon Rectum 2012;55:1131-7.

(57) Muscovici S. The phenomenon of social representations. In: Farr R, Muscovici S, editors. Social Representation.Cambridge, UK: Cambridge University Press; 1984:369.

(58) Douglas M. Purity and Danger. London: Routledge; 1966.

(59) Goffman E. The Presentation of Self in Everyday Life. London: Penguin; 1959.

(60) Goffman E. Stigma: Notes on the Management of a Spoiled Identity. Englewood Cliffs: Prentice-Hall Inc.; 1963.

(61) Knowles S, Tribbick D, Connell W, et al. Exploration of health status, illness perceptions, coping strategies, and psychological morbidity in stoma patients. J Wound Ostomy Continence Nurs 2014;41:573-80. 
(62) Haidt J, McCauley C, Rozin P. Individual differences in sensitivity to disgust: A scale sampling seven domains of disgust elicitors. Pers Individ Diff 1994;16: 701-713.

(63) Smith D, Loewenstein G, Rozin P et al. Sensitivity to disgust, stigma, and adjustment to life with a colostomy. J Res Pers 2007;41:787-803.

(64) Abdalla M, Sandler R, Kappelman M, et al. The impact of ostomy on quality of life and functional status of Crohn's disease patients. Inflamm Bowel Dis 2016;22:265864.

(65) Knowles S, Tribbick D, Connell W, et al. Exploration of health status, illness perceptions, coping strategies, psychological morbidity and quality of life in individuals with fecal ostomies. J Wound Ostomy Continence Nurs 2017;44:69-73.

(66) Seth N, Machicado J, Regueiro M, et al. Quality of life after permanent ileostomy in IBD patients: a 5-year prospective cohort study. Am J Gastroenterol 2015;110(Suppl. 1s):S841-S842.

(67) Murphy P, Khot Z, Vogt K, et al. Quality of life after total proctocolectomy with ileostomy or IPAA: a systematic review. Dis Colon Rectum 2015;58:899-908.

(68) Burch J. Exploring the conditions leading to stoma-forming surgery. B J Nurs 2005;14:94-8.

(69) Levenstein S. Embracing complexity: what determines quality of life in inflammatory bowel disease? Euro J Gastroenterol Hepatol 2004;16:1253-5. 